\title{
Vida artificial: a mobilidade do conceito de transumano e pós-humano
}

\author{
Artificial life: the mobility of transhuman and post-human concept
}

Eduardo Marks de Marques', Luana de Carvalho Krüger"

\begin{abstract}
Resumo: A discussão acerca do conceito de vida artificial, que procura reproduzir tudo aquilo que é entendido como vida a partir de uma perspectiva biológica, está cada vez mais se tornando fundamental para a criação de robôs-humanóides com habilidades e características muito semelhantes aos humanos. Em contrapartida, as teorias transumanistas e pós-humanista procuram permitir que os corpos humanos sejam mais autônomos, de modo a permitir com que os humanos tenham uma maior consciência dos seus corpos e das suas necessidades. Neste trabalho será investigado os cruzamentos entre tais conceitos do viés robótico e humano, procurando observar o quanto a vida artificial pode garantir uma expansão do conceito de transumano e pós-humano dentro dos estudos de reprodução artificial da vida biológica.
\end{abstract}

Palavras-chave: Transumanismo; Pós-humanismo; Vida artificial

\begin{abstract}
The discussion about the concept of artificial life, which seeks to reproduce everything that is understood as life from a biological perspective, is increasingly becoming fundamental for the creation of humanoid robots with abilities and characteristics very similar to humans. In contrast, transhumanist and post-humanist theories seek to allow human bodies to be more autonomous in order to make humans become more aware of their bodies and their needs. In this paper we will investigate the crossings between the concepts of robotic and human bias, trying to observe how much artificial life can guarantee an expansion of the concept of transhumanism and post-humanism within the studies of artificial reproduction of biological life.
\end{abstract}

Keywords: Transhumanism; Post-humanism; Artificial life

\section{Introdução}

Estudos acerca do corpo a partir da perspectiva das teorias transumanista e póshumanista são pertinentes na sociedade contemporânea que tanto enfatiza a imperfeição do corpo biológico e suas falhas, seja pelo viés estético ou pelo desempenho, ainda que restrito, dos corpos humanos. Uma das comprovações de que o corpo humano está longe de uma perfeição são as inúmeras interferências disponíveis para o seu melhoramento, sendo ele a fonte de riqueza de empresas voltada para intervenção nos corpos, desde medicamentos e cosméticos até processos mais invasivos como cirurgias. Os corpos tornaram-se objetos e o uso da tecnologia é fundamental para que isso ocorra. É através dos estudos com base tecnológica que é possível desenvolver melhorias para as falhas

Professor Associado II de Literaturas de Língua Inglesa do Centro de Letras e Comunicação da Universidade Federal de Pelotas.eduardo.marks@ufpel.edu.br

" Mestra em Literatura Comparada pelo Programa de Pós-Graduação em Letras da Universidade Federal de Pelotas. luana-kruger@hotmail.com 
nos corpos que, em alguns casos, são essenciais para os indivíduos, como lentes para óculos e próteses cada vez mais adaptadas as necessidades humanas e individuais.

Tais intervenções tecnológicas são tão constantes que, atualmente, fala-se em corpos transumanos. Este conceito não nega o humano, pelo contrário, seria um outro processo de evolução humana que estaria a cargo de intervenções tecnológicas dando aos humanos maior autonomia e controle dos seus próprios corpos e tornando-os mais adaptados. No artigo “The philosophy of transhumanism”, Max More (2013) explica que o

“Trans-humanismo" enfatiza as raízes da filosofia no humanismo do Iluminismo. Daqui vem a ênfase no progresso (sua possibilidade e desejabilidade, não sua inevitabilidade), em tomar a responsabilidade pessoal de criar futuros melhores ao invés de esperar ou rezar para que eles sejam trazidos por forças sobrenaturais, pela razão, tecnologia, método científico, e criatividade humana, em vez de fé. (MORE, 2013, p.04, grifos do autor, tradução nossa) ${ }^{1}$.

No período iluminista se pensava no homem como o centro de universo e, portanto, a transformação humana estaria a cargo da educação e da cultura sem precedências religiosas, já o transumanismo traz as mudanças a partir da tecnologia que garante alterações biológicas. Tais mudanças não anulam o que o enfoque humanista propôs, pelo contrário, está justamente pensando no progresso dos humanos, mas com uma perspectiva diferente (MORE, 2013, p. 05). Cabe reforçar ainda que a filosofia transumanista direciona seus estudos para as limitações humanas, para tanto

[o]s transumanistas tipicamente procuram expandir a gama de possíveis ambientes futuros para a vida pós-humana, incluindo a colonização do espaço e a criação de mundos virtuais ricos. Quando os transumanistas se referem à "tecnologia" como o principal meio de efetuar mudanças na condição humana, isso deve ser entendido amplamente para incluir o design de organizações, economias, políticas e o uso de métodos e ferramentas psicológicos. (MORE, 2013, p. 05, grifos do autor, tradução nossa) $)^{2}$.

Estas mudanças dizem muito sobre o que os indivíduos são e/ou estão se tornando e como somos cada vez mais tecnológicos, "[...] somos todos quimeras, híbridos - teóricos e fabricados - de máquina e organismo; somos, em suma, ciborgues” (HARAWAY, 2009, p.37). A natureza humana é "[...] um ponto ao longo de um caminho evolutivo e podemos aprender a remodelar nossa própria natureza de maneiras que consideramos desejáveis e valiosas [...] podemos nos tornar pós-humanos.” (MORE e VITA-MORE, 2013, p.04, tradução nossa $)^{3}$, que por definição seriam indivíduos com completo controle de seus corpos e de suas capacidades mentais (RÜDIGER, 2008, p.142). E, com isso, defende-se que "[à] medida que a tecnologia avança, alterando o corpo humano, [ela] pode nos conceder habilidades inteiramente novas.” (BLACKFORD, 2013, p. 441/422, tradução nossa) ${ }^{4}$.

Nessa relação entre corpo e tecnologia observa-se, por exemplo, Neil Harbison cofundador da Cyborg Foundation e primeiro ciborgue reconhecido pelo governo britânico.

\footnotetext{
${ }^{1}$ Do original: "Trans-humanism" emphasizes the philosophy's roots in Enlightenment humanism. From here comes the emphasis on progress (its possibility and desirability, not its inevitability), on taking personal charge of creating better futures rather than hoping or praying for them to be brought about by supernatural forces, on reason, technology, scientific method, and human creativity rather than faith.

2 Do original: The transhumants tend to expand the range of future environments for post-human life, including a colonization of space and a creation of rich worlds. When transhumanists refer to "technology" as the primary means of promoting changes in the human population, they need to be widely used to designate economies, policies and the use of psychological methods and tools.

${ }^{3}$ Do original: [...] just one point along an evolutionary pathway and we can learn to reshape our own nature in ways we deem desirable and valuable. [...] we can become posthuman.

${ }^{4}$ Do original: As technology goes inwards, altering the human body, it may grant us entirely new abilities.
} 
Harbison possui acromatopsia, uma síndrome rara que impede o indivíduo de ver cores, de modo que ele só consegue perceber diferentes tons de cinza. Neil ficou conhecido por ter uma antena implantada no seu crânio que o permitiu ouvir cores, isto é, a partir de ondas sonoras distintas emitidas quando o sensor reconhece diferentes cores, Harbisson consegue ouvir sons que foram classificados em cores visíveis e, inclusive, invisíveis, como a percepção de raios ultravioleta (CYBORG FOUNDATION, 2017).

Na palestra intitulada "I listen to color" do TEDTalks, ele explica um pouco do funcionamento deste equipamento, que começou sendo carregado em uma mochila em suas costas e agora é um chip implantado em seu pescoço. "Harbisson identifica-se como um ciborgue, ele sente que sua mente e seu corpo estão unidos ciberneticamente. Ele não sente que ele está usando tecnologia, em vez disso ele sente que ele é tecnologia." (CYBORG FOUNDATION, 2017, tradução nossa) ${ }^{5}$. Neil faz uso de uma tecnologia bastante avançada para suprir uma falha de seu corpo, ele não é mais unicamente humano. Seja ciborgue ou transumano é possível observar que ele faz o uso de tecnologias implantadas no seu corpo para conseguir desempenhar uma função que nenhum outro humano foi capaz de desempenhar: escutar cores.

Ao mesmo tempo em que os humanos se aproximam da tecnologia e do artificial para alterarem seus corpos, robôs humanóides estão sendo desenvolvidos. A EUA Hanson Robotics, por exemplo, apresenta em seu website a robô Sophia, definida pelos criadores como uma robô que "desafia o pensamento convencional do que um robô deve ter. [...] Se alguma vez houve um robô com uma elegância simples que as pessoas não podem deixar de apreciar, seria Sophia." (HANSON ROBOTICS, 2017, tradução nossa) ${ }^{6}$. Um fato importante a respeito da robô Sophia é que em Outubro de 2017 ela ganhou a cidadania na Arábia Saudita em um evento denominado Future Investment Initiative em Riyadh. "Ganhar a cidadania faz com que a robô tenha mais direitos do que as mulheres da Arábia Saudita, como a possibilidade de se locomover sem um guardião do sexo masculino que lhe dê permissão para agir e de se apresentar sem estar com o rosto e o corpo cobertos. (REVISTA GALILEU, 2017).

Ao aproximar os robôs das feições e comportamentos humanos, abre-se espaço para discussões acerca do direito que seria garantido para tais máquinas e como a humanidade lidaria com isso. No caso da robô Sophia, há inúmeras implicações na definição de cidadã garantida a uma máquina e que permitem uma discussão interessante sobre a humanidade das máquinas quando criadas para se comportarem e parecem com os humanos, assim como a relação dos humanos frente as inúmeras tecnologias disponíveis para os seus corpos e para criação de corpos artificiais.

Neste artigo, será discutido como os corpos humanos estão sendo melhorados e alterados na sociedade contemporânea e se essas melhorias estão de acordo com as discussões propostas para o progresso dos corpos humanos, tendo como base os conceitos de transumanismo e pós-humanismo. Além disso, será proposta uma outra perspectiva dentro destes conceitos que traz a ampliação da abordagem do tema a partir das discussões de vida artificial, em que uma nova abordagem para o conceito de vida a partir do modo como corpos artificiais e não-humanos são idealizados. Assim, procura-se compreender quais os limites destes conceitos e se eles são relevantes para a discussão do humano híbrido (artificial e orgânico), ao passo que robôs já começam não somente a ganhar características humanas, como também adquirir direitos humanos.

\footnotetext{
${ }_{5}^{5}$ Do original: Harbisson identifies himself as a cyborg, he feels both his mind and body are united to cybernetics. He doesn't feel he is using or wearing technology, instead he feels he is technology.

${ }^{6}$ Do original: [...] defies conventional thinking of what a robot should look like. [...] If ever there were a robot with a simple elegance people can't help but appreciate, it would be Sophia.
} 


\section{Transumanismo e Pós-humanismo - ressignificação de humano}

Um ponto importante para a discussão acerca da teoria transumanista e póshumanista é o que está se concretizando nas interferências ao corpo humano e se elas estão de fato melhorando o desempenho humano ou apenas reforçando padrões estéticos. Para tanto, cabe diferenciar o que as teorias preveem e o que é comercializado para as alterações nos corpos, pois embora ambos estejam dominados por influências tecnológicas, não estão necessariamente carregando os mesmos princípios em relação as alterações nos corpos, sendo o desejo de perfeição um dos meios mais instigados para convencer os humanos de alterarem algo em seus corpos.

As mudanças pensadas pelos transumanistas e pós-humanistas visam um melhoramento dos corpos humanos, isto é uma ampliação das habilidades físicas e mentais dos humanos, fazendo com que eles possam ser, cada vez mais, autônomos e conscientes dos seus corpos. Este melhoramento dos corpos humanos, no entanto, já é algo presente em inúmeros estudos, assim como explica Kunzru (2009) no artigo "Genealogia do ciborgue":

O sonho de melhorar as capacidades humanas por meio de uma reprodução seletiva tem constituído, desde muito, um item obrigatório do lado sombrio da literatura médica ocidental. Existe, agora, a possibilidade de se fabricar humanos melhores, ampliando suas capacidades por meio de dispositivos artificiais. Doses de insulina têm sido utilizadas para controlar os metabolismos dos diabéticos desde os anos vinte. Uma máquina constituída de uma combinação de pulmão e coração foi utilizada para controlar a circulação sanguínea de uma moça de 18 anos durante uma operação em 1953. Um homem de 43 anos recebeu o primeiro implante de marca passo em 1958. (KUNZRU, 2009, p.122/123).

Diferentemente do que algumas obras de ficção científica trazem acerca do corpo humano e de alterações ainda muito distantes da realidade, que também estão ligadas a uma filosofia transumanista, observa-se que a ideia de melhorar o corpo e tornar os indivíduos mais autônomos e cientes de suas capacidades já circula nos estudos atuais e possibilita melhorias, como os implantes e próteses, por exemplo, que visam suprir a insuficiência e/ou a ausência do corpo humano. Além disso, estas alterações já procuram, por vezes, desempenhar funções melhores que o próprio corpo humano sem intervenção tecnológica, de modo que o corpo humano já é entendido como imperfeito e passível de melhorias, não sendo mais a base para um parâmetro de desempenho efetivo daqueles que necessitam de uma intervenção tecnológica.

Entende-se o transumanismo como um processo para o pós-humanismo, sendo o indivíduo pós-humano aquele que teria total controle de seu corpo e, potencialmente, imortal (RÜDIGER, 2008, p.142). Ainda que pareça um processo distante, os recursos tecnológicos estão garantindo que, cada vez mais, seja possível controlar o seu corpo e/ou altera-lo e adapta-lo para um melhor desempenho social. Estas possibilidades colocam em jogo o comportamento humano, bem como o quanto essas alterações podem influenciar nas relações sociais. Talvez aqui esteja um dos maiores desafios do transumanismo e póshumanismo, tendo em vista que não há como prever o comportamento humano diante de avanços tecnológicos que permitiriam ao próprio humano ser o seu próprio Deus.

Suponha que pudéssemos alcançar nossas mais extravagantes esperanças. O que então pediríamos? Que os próprios humanos se tornassem seus próprios sucessores, que qualquer injustiça ocorrida seria superada por nosso conhecimento de nossas raízes. Para aqueles que permanecessem inalterados, o objetivo seria um tratamento benigno (talvez até dando aos que ficaram para trás a aparência de serem mestres de escravos divinos). Poderia ser uma época de ouro que também envolvesse progresso [...]. 
A imortalidade (ou pelo menos uma vida contanto que possamos fazer o universo sobreviver) seria alcançável. (VINGE, 2013, p.373, tradução nossa)7 .

Os questionamentos acerca das alterações nos corpos e para onde elas poderiam levar os humanos e suas relações sociais é bastante discutida através de obras literárias distópicas, como por exemplo, Deuses de Pedra (2007) de Jeanette Winterson, Androides Sonham com Ovelhas Elétricas? (1968) de Philip K. Dick e Admirável Mundo Novo (1932) de Aldous Huxley. Tais obras, entre tantas outras, apontam para os problemas nas alterações dos corpos, ainda que eles sejam vistos como um melhoramento da espécie Homo sapiens, em grande parte os problemas surgem justamente pela tentativa de suprir determinadas necessidades, sem observar o motivo pelo qual elas estão sendo alteradas. Juntamente com isso, essas obras trazem discussões acerca das relações sociais e do modo como elas são estabelecidas, mostrando as dificuldades dos humanos em lidar com o excesso de recursos tecnológicos. Negrim (2008) no artigo "Cosmetic Surgery and the Eclipse of Identity” traz uma abordagem interessante acerca das alterações nos corpos, dizendo que

[u]m dos paradoxos de emergir do crescente investimento no corpo como fonte de identidade é que, à medida que nossa capacidade de remodelar nosso corpo aumenta com os avanços nos procedimentos cirúrgicos e outras biotecnologias, nosso senso de quem somos torna-se cada vez menos certo. [...] Embora a ciência tenha nos fornecido os meios pelos quais podemos transformar nossos corpos, ela é incapaz de nos dar qualquer orientação sobre como esses meios devem ser empregados.

É por isso que, para muitos, a reforma cirúrgica de seus corpos se torna um processo sem fim, pois eles se engajam em uma busca impossível por uma identidade que está para sempre além do alcance. (NEGRIM, 2008, p.92, tradução nossa) ${ }^{8}$.

As mudanças atuais mais realizadas nos corpos, como cirurgias plásticas e tratamentos estéticos, não estão garantindo nenhuma autonomia aos indivíduos e, pelo contrário, estão tornando-os cada vez mais dependentes de intervenções estéticas e padrões estéticos. Ao mesmo tempo, não se trata de uma promessa transumanista e póshumanista que todas as alterações sejam positivas e garantidoras de autonomia, pois não há como prever a influência disso na sociedade.

Embora firmemente empenhado em melhorar a condição humana e, em geral, otimista em relação às nossas perspectivas de fazê-lo, o transumanismo não implica qualquer crença na inevitabilidade do progresso nem no futuro livre de perigos e desvantagens. As mesmas tecnologias poderosas que podem transformar a natureza humana para melhor, também podem ser usadas de maneira que, intencionalmente ou involuntariamente, causem danos diretos ou prejudiquem sutilmente nossas vidas. A preocupação transumanista com a racionalidade e seu rec onhecimento concomitante de incerteza implica reconhecer e prevenir proativamente os riscos e minimizar os custos. (MORE, 2013, p.04, tradução nossa) ${ }^{9}$.

\footnotetext{
Do original: Suppose we could attain our most extravagant hopes. What then would we ask for? That humans themselves would become their own successors, that whatever injustice occurred would be tempered by our knowledge of our roots. For those who remained unaltered, the goal would be benign treatment (perhaps even giving the stay-behinds the appearance of being masters of godlike slaves). It could be a golden age that also involved progress [...]. Immortality (or at least a lifetime as long as we can make the universe survive) would be achievable.

${ }^{8}$ Do original: One of the paradoxes to emerge from the growing investment in the body as a source of identity is that as our capacity to refashion our bodies increases with the advances in surgical procedures and other biotechnologies, our sense of who we are becomes less and less certain. While science has provided us with the means by which to transform our bodies, it is unable to give us any guidance as to how these means should be employed. That is why, for many, the surgical refashioning of their bodies becomes a never-ending process as they engage in an impossible search for an identity that is forever beyond reach.

9 Do original: While firmly committed to improving the human condition and generally optimistic about our prospects for doing so, transhumanism does not entail any belief in the inevitability of progress nor in a future free of dangers and downsides. The
} 
Trata-se, portanto, do modo como socialmente se lida com os avanços tecnológicos, que acabam sendo dominados por uma estrutura econômica que visa a criação e inovação de produtos para o consumo e geração de capital. As inúmeras propagandas e promessas estéticas e "antes e depois" em formas de vídeos e postagens em redes sociais mostram o quanto o mercado e a propaganda caminham juntos para a imposição de desejos em ajustes nos corpos humanos. Trinca (2008), na dissertação de mestrado intitulada $O$ corpoimagem na "cultura do consumo": uma análise histórico-social sobre a supremacia da aparência no capitalismo avançado aponta para os problemas sociais relacionados as alterações dos corpos dizendo que

nossa sociedade tanto cultua o corpo como não cessa de desprezá-lo, comercializá-lo e coisificá-lo. O corpo reina e padece diariamente. Propagamse as "deficiências" e os limites corporais, desvalorizam-se as singularidades e potencialidades dos sujeitos e os tornam desnecessários, descartáveis, sem sentido, e, simultaneamente, o aclamam, fazendo do corpo o mais sublime objeto de adoração. (TRINCA, 2008, p.03, grifos da autora).

O corpo, na sociedade contemporânea, tem sido uma fonte de alterações e melhoramentos que não fazem o indivíduo mais adaptado e autônomo, pelo contrário, torna-o mais dependente de recursos estéticos que mais o padroniza do que garante sua liberdade e domínio de si. O que entra em jogo acaba sendo uma disputa pautada na beleza e na perfeição estética, que pouco ou nada possui de relação com o que é proposto pelos teóricos do transumanismo e pós-humanismo.

A ênfase na precariedade da carne, na imperfeição, na falta de resistência, no envelhecimento progressivo e na morte como ameaça constante alimentam o imaginário social referente ao descrédito para com o corpo real e amparam diversas pesquisas científicas e numerosas práticas cujo intuito é remediar as deficiências do orgânico por meio de procedimentos técnicos e métodos de gestão e controle. (TRINCA, 2008, p.03)

O que tais mudanças atualmente promovem está longe de uma independência estética e acaba sendo o oposto do que Donna Haraway (2009), no Manifesto Ciborgue, defende ao pensar no conceito de ciborgue que quebraria com o binarismo do gênero, dizendo que:

[o] ciborgue é uma criatura de um mundo pós-gênero: ele não tem qualquer compromisso com a bissexualidade, com a simbiose pré-edípica, com o trabalhonãoalienado.Ociborguenãotemqualquerfascínioporumatotalidade orgânica que pudesse ser obtida por meio da apropriação última de todos os poderes das respectivas partes, as quais se combinariam, então, em uma unidade maior. (HARAWAY, 2009, p.38)

O que se tem acesso e é mais evidenciado dentro da ampla discussão de melhorias no corpo é um reforço de imposição de gêneros binários e consequentemente de definições de homem e mulher que refletem nas relações sociais e patriarcais. O corpo humano passa por constantes processos de alterações que acabam sendo reforços de uma padronização da beleza, fugindo das possíveis melhorias das capacidades humanas. Voltase as discussões que cercam os riscos do transumanismo e do pós-humanismo, ou ainda, dos avanços tecnológicos e da utilização de tais avanços nos corpos. Observa-se que ainda se está distante do ideal transumano e pós-humano, pois as imperfeições corrigidas dos

same powerful technologies that can transform human nature for the better could also be used in ways that, intentionally or unintentionally, cause direct damage or more subtly undermine our lives. The transhumanist concern with rationality and its concomitant acknowledgment of uncertainty implies recognizing and proactively warding off risks and minimizing costs. 
corpos estão mais ligadas a um objetivo estético e de mercado, fazendo o corpo humano reforçar um padrão de beleza midiático.

As discussões sobre os avanços da bioética entram também nas teorias transumanistas e pós-humanistas pois, segundo Noêmia de Sousa Chaves (2010), no artigo "O Conceito de Pessoa Humana: Abordagens Bioética(s) em Engelhardt Jr. e Lucien Sève", "[a] bioética é plural em face das circunstâncias provenientes de um processo tecnológico tão refinado e, na mesma medida, tão audacioso que invade a vida humana desde seu início até quando ele (o processo tecnológico) resolve aceitar ou decretar o seu fim.” (CHAVES, 2010, p. 64).

É, principalmente, por estar presente em dois importantes momentos da vida humana, o nascimento e a morte, que é possível observar o quanto o estudo da bioética dialoga com as teorias que procuram o melhoramento do corpo e, consequentemente, a longevidade com qualidade de vida. A bioética também tem um papel importante para garantir que tais melhoramentos estejam dentro de limites éticos, assim:

[...] estuda os avanços recentes da ciência em função, sobretudo, da pessoa humana. A referência central é o ser humano, especialmente considerado em dois momentos básicos: o nascimento e a morte. É sobre essas duas fases da vida que hoje a ciência está fazendo seus melhores progressos e, obviamente, colocando problemas éticos inimagináveis antes dessas descobertas. (PEGORARO, 1998, p.57)

Com os avanços da biotecnologia e da medicina não são somente os aspectos biológicos e naturais estão em jogo para o estudo na alteração dos corpos humanos, mas também o que de artificial começa a ser produzido. O caso da robô Sophia, por exemplo, desestabiliza as fronteiras entre o humano e o robótico, ainda mais quando alterações genéticas expandem os limites da própria definição de humano. Além disso, ao tratar de ética não se está pensando em um campo genético, mas em questões sociais que estão, ou deveriam estar, acima de qualquer melhoramento estético.

É importante reconhecer que o homem, como produto da natureza, amadurece como os outros seres naturais. A maturidade humana alcançase sobretudo no estágio ético, isto é, na fase em que o homem, autônomo e livre, age segundo valores adequados ao seu modo de existir. Ora, os valores não se encontram nos genes, nem são produtos espontâneos da genética, mas são culturais, são frutos de uma longa experiência e tradição humana. Isto é, o processo evolutivo não nos deu de saída um código de valores éticos, mas deu-nos a capacidade de adquiri-los. Por isso mesmo, a ciência nunca descobrirá (ou isolará) um valor ético no laboratório. (PEGORARO, 1998, p.59)

Se a definição de humano não se limita a fatores genéticos, mas a questões culturais, a alteração nos corpos, seja pelo viés puramente estético, mas principalmente pelo melhoramento das capacidades humanas, não deveria ser um problema, pois a filosofia transumanista, assim como o pós-humanista estão a serviço de uma evolução, ou ainda, de um melhoramento dos corpos que visa benefícios aos humanos. Acredita-se, portanto, que o ideal de humano está relacionado aos corpos tecnológicos, pois ainda está se tratando de corpos racionais e da racionalidade humana, isto é, não se procura apagar o humano e refazer uma espécie, mas aprimorar e ampliar os limites destes corpos.

Pensar em corpos humanos alterados é pensar muito mais nos limites dessas mudanças, ou seja, em questões éticas que perpassam o campo científico, pois "a ciência existe para descobrir a natureza e promover a vida, a saúde e a liberdade das pessoas e da sociedade; ou melhor, a tecnociência tem sentido quando está a serviço da vida, do ser-humano, do meio-ambiente.” (PEGORARO, 1998, p.63). Sem questionar a validade 
dos valores éticos, ressalta-se que todos eles passam por questões sociais que envolvem tanto a religiosidade, valores sociais como também necessidades, de modo que se acredita que tais processos de modificações dos corpos estarão sempre se alterando ao passo que outros pontos relacionados a eles também se alteram.

Essa incongruência leva a pensar o próprio conceito de vida e se o mesmo se restringe as questões biológicas, pois se cada vez mais as máquinas se aproximas dos humanos e se já começam a ganhar status de humano, é possível que conceitos que ainda associam humano, vida e natureza ao que tem origem na categoria do biológico já não sejam suficientes e não correspondam aos avanços tecnológicos.

A crítica, portanto, é estabelecida em duas instancias: a primeira, diante das alterações atuais nos corpos humanos que não parecem correspondem ao que é idealizado na filosofia transumanista e pós-humanista; a segunda, diante dos limites dessas alterações nos corpos e o quanto eles podem alterar a própria percepção de humano diante de corpos alterados. Percebe-se que os humanos, dentro da perspectiva transumanista e pós-humanista seriam ressignificados diante de padrões binários de gênero, aspectos e relações sociais, pois a percepção e domínio de seus corpos seriam distintas, no entanto, a influência robótica também participa dessas mudanças e isto é o que as discussões sobre vida artificial estão promovendo.

\section{Vida artificial - a ampliação do conceito de transumano e pós-humano}

Corpos humanos-robotizados que mantêm uma racionalidade ainda podem ser considerados humanos, já corpos robóticos-humanizados não, ou seja, a racionalidade que é considerada fundamental, não é a racionalidade da máquina, mas sim do humano. Há uma relação direta com questões que transcendem o físico e passam para a psique e, em alguns casos, para o campo religioso. A racionalidade, o espírito, a alma ainda são conceitos que se restringem a seres biológicos e humanos, de modo que não é todo ser natural que é racional, muito menos a racionalidade da máquina pode ser considerada algo natural e/ou divino. A forma humana e o comportamento humano não garantem às máquinas a equidade com os humanos.

No entanto, observa-se que as alterações dos corpos humanos são, de certa forma, um meio de torna-los mais artificiais, de fazer com eles sejam ciborgues e, portanto, possuam como parte deles o aspecto não-humano também. Entra-se nas questões entre os limites do humano e da máquina que são discutidos por Tadeu (2009), no artigo "Nós, ciborgues: O corpo elétrico e a dissolução do humano” em que é apontado que

[...] uma das mais importantes questões de nosso tempo é justamente: onde termina o humano e onde começa a máquina? Ou, dada a ubiquidade das máquinas, a ordem não seria a inversa?: onde termina a máquina e onde começa o humano? Ou ainda, dada a geral promiscuidade entre o humano e a máquina, não seria o caso de se considerar ambas as perguntas simplesmente sem sentido? Mais do que a metáfora, é a realidade do ciborgue, sua inegável presença em nosso meio ("nosso"?), que põe em xeque a ontologia do humano. Ironicamente, a existência do ciborgue não nos intima a perguntar sobre a natureza das máquinas, mas, muito mais perigosamente, sobre a natureza do humano: quem somos nós? (TADEU, 2009, p.10/11, grifos do autor).

O conceito de vida artificial ainda é recente dentro dos estudos do corpo humano, justamente por ainda estar bastante ligado as pesquisas de robótica e computação bruta. Há, todavia, alguns pesquisadores que já dialogam também com as discussões do pós-humano, o que faz com que o intercâmbio de informações entre o artificial e o biológico possam 
ser pensados dentro dos estudos de melhoramento do corpo humano. Na ciência bruta da computação, o conceito de vida artificial

[...] é a denominação de uma abordagem sintética para a biologia, inspirada pelos experimentos com simulação por computador. Para os pesquisadores desta área, os procedimentos de síntese ensinaram que seu campo de estudos não precisa se restringir à tentativa de recriar os fenômenos biológicos tais quais ocorrem na natureza, mas está livre para explorar a natureza tal como poderia ter sido. A vida artificial é um campo que usa conceitos informacionais e modelização de computadores para estudar desde a organização virótica até a evolução da biosfera. (OLIVEIRA, 2006, p.12, grifos da autora).

Nessa perspectiva, parece que o corpo humano seria somente um dos modelos a serem reproduzidos pela vida artificial e, possivelmente, o mais desafiador e mais inatingível. Cabe, no entanto, observar por um outro viés, aquele em que a vida artificial promove não somente os meios para reproduzir a vida biológica em um meio artificial, mas acabar impulsionando que os avanços tecnológicos também promovam as mudanças nos corpos humanos também, de maneira que o conceito de desconecta da ciência bruta e passa a dialogar com outras áreas do conhecimento. Segundo Mark A. Bedau (2007), no artigo "Artificial Life",

[f]ilosofia e vida artificial são parceiros intelectuais naturais, por três razões. Ao criar tipos totalmente novos de fenômenos semelhantes à vida, a vida artificial nos obriga a reexaminar e reavaliar o que é ser vivo, adaptativo, inteligente, criativo, etc. Além disso, tanto a filosofia como a vida artificial procuram compreender fenômenos a um nível de generalidade que ignora contingências e revela naturezas essenciais.

Finalmente, a metodologia computacional da vida artificial é uma extensão direta e natural da metodologia tradicional da filosofia de uma experiência de pensamento a priori. Com o objetivo de capturar a essência simples dos processos vitais, a vida artificial abstrai os muitos detalhes dos sistemas vivos quanto possível. (BEDAU, 2007, p.592, tradução nossa) ${ }^{10}$.

Nesse processo de reexaminar o que até então se compreende por vida, também está atrelado o que pode ser definido como humano, mais uma vez teorias acerca do melhoramento de corpos revisitam o conceito biológico, para pensar nas possibilidades de mobilidade entre o artificial e o natural, gerando outras possibilidades que nem a própria teoria transumanista, bem como pós-humanista teria cogitado, o humano entendido primeiramente pelo princípio daquilo que não tem origem no humano biológico, mas que possivelmente ainda representara o corpo humano.

O uso da tecnologia nos corpos humanos já é algo que é considerado corriqueiro, mais ainda quando se trata do uso da tecnologia a serviço dos humanos, seja no trabalho ou em seus lares. Em alguns casos, há o esquecimento de que tal recurso é fruto do desenvolvimento tecnológico, justamente por estar diretamente ligado a atividades cotidianas. O humano não vive sem tecnologia.

O desenvolvimento tecnocientífico ao produzir uma maquinização do humano e uma humanização da técnica não aponta apenas para as complexas questões fronteiriças sobre onde termina o humano e começa

\footnotetext{
${ }^{10}$ Do original: Philosophy and artificial life are natural intellectual partners, for three reasons. By creating wholly new kinds of life-like phenomena, artificial life continually forces us to reexamine and reassess what it is to be alive, adaptive, intelligent, creative, etc. In addition, both philosophy and artificial life seek to understand phenomena at a level of generality that ignores contingencies and reveals essential natures. Finally, artificial life's computational methodology is a direct and natural extension of philosophy's traditional methodology of a priori thought experiment. Aiming to capture the simple essence of vital processes, artificial life abstracts away as many details of living systems as possible.
} 
a tecnologia. Indica urna nova relação entre humanos e técnica: a tecnologia é constituinte do humano. Esta lição nos é dada pelas recentes pesquisas das ciências cognitivas e neurociências. Na sociedade atual nossas atividades mais corriqueiras, sejam de caráter orgânico, sensorial, cognitivo ou laborativo, estão tão imbuídas de artefatos tecnológicos que a distinção entre natural e artificial perde a nitidez. O uso de máquinas em atividades laborativas não é novidade. Já há algum tempo, as máquinas invadem nossos lares, locais de trabalho e hospitais para nos ajudar a respirar, andar e ver. Hoje, não se pode negar também sua participação em tarefas cognitivas. (OLIVEIRA, 2003, p.187, grifos da autora).

Entra-se em um ponto fundamental da discussão proposta: seria o corpo humano respeitado no processo de alteração e melhoramento? Ainda que impossível de afirmar uma resposta irrefutável, acredita-se que se existe a necessidade de se aproximar o corpo robótico do corpo humano, o melhoramento não se distanciará das características físicas que o corpo humano apresenta. Toda representação do humano, inclusive de seres artificiais que procuram se assemelhar aos humanos, tendem a se aproximar dos padrões físicos do corpo humano.

Cada vez mais, a questão não é se nos tornaremos pós-humanos, pois a pós-humanidade já está aqui. Em vez disso, a questão é que tipo de pós-humanos seremos. As narrativas da Vida Artificial revelam que, se reconhecermos que o observador deve fazer parte da imagem, os corpos nunca poderão ser feitos apenas de informação, não importa de que lado da tela do computador eles estejam. (HAYLES, 1999, p.246, grifos da autora, tradução nossa) $)^{11}$.

Além disso, questiona-se também se as máquinas poderiam ser confiáveis, principalmente quando tendem a reproduzir a vida humana. Esta discussão está muito ligada ao modo como as máquinas se comportariam de forma espontânea, sem estarem diretamente ligadas ao controle de um humano ou de uma fonte de inteligência capaz de coordenar as ações humanas.

A principal ruptura subjacente à lógica atual é o esmaecimento de fronteiras entre orgânico e maquínico, natural e artificial, animado e inanimado. [...] a continuidade entre o ser vivo e a matéria inerte foi impulsionada pelas pesquisas da biologia molecular ao descobrir que os níveis mais elementares do ser vivo são formados pelos mesmos compostos químicos da matéria inorgânica.

O segundo rompimento de fronteiras refere-se aos estudos nas áreas de ciências cognitivas, inteligência artificial e filosofia que têm se esforçado em mostrar que o pensamento e a inteligência não dependem da consciência de si. Atividades como tomada de decisões e raciocínio lógico-matemático são executadas por máquinas inteligentes, deixando de ser atividades exclusivas do humano. As fronteiras entre seres biológicos e maquínicos, corpo e pensamento, matéria viva e inerte são colocadas em movimento. (OLIVEIRA, 2003, p.193/194).

O processo de reconhecer na máquina de vida artificial algo de consciente e independente de toda e qualquer relação com o criador é parte do próprio conceito que está ligado a concepção de uma vida artificial, pois se tal teoria procura recriar a vida biológica em um meio artificial, ela também procura respeita todos os processos evolutivos que poderiam ocorrem na vida biológica. Pensar, portanto, em

\footnotetext{
${ }_{11}$ Do original: Increasingly the question is not whether we will become posthuman, for posthumanity is already here. Rather, the question is what kind of posthumans we will be. The narratives of Artificial Life reveal that if we acknowledge that the observer must be part of the picture, bodies can never be made of information alone, no matter which side of the computer screen they are on.
} 
corpos artificiais que se assemelham aos corpos humanos está diretamente ligado ao comportamento da máquina de acordo com o comportamento humano. "De fato, no mundo futuro [...] distinguir entre vida natural e Vida Artificial, inteligência humana e máquina, será difícil ou impossível.” (HAYLES, 1999, p.235, tradução nossa) ${ }^{12}$. Em um livro intitulado How we became posthuman?, Hayles (1999) traz uma análise muito relevante que conecta a vida biológica aos conceitos presentes nas discussões sobre a vida artificial e a semelhança com a evolução biológica.

Os seres humanos evoluíram através de uma combinação de processos de melhoria e auto-organização até chegarem ao ponto em que poderiam aproveitar conscientemente os princípios da auto-organização para criar mecanismos evolutivos. Eles usaram essa habilidade para construir máquinas capazes de auto evolução. Diferentemente dos humanos, no entanto, as máquinas não são prejudicadas pelas restrições de tempo impostas pela evolução biológica e maturação física. Elas podem percorrer centenas de gerações em um dia, milhões em um ano. Até muito recentemente, os seres humanos não tinham a capacidade de armazenar, transmitir e manipular informações. Agora eles compartilham essa habilidade com máquinas inteligentes. Para prever o futuro desse caminho evolutivo, temos apenas que perguntar qual desses organismos, competindo de muitas maneiras pelo mesmo nicho evolucionário, tem a capacidade de processamento de informações para evoluir mais rapidamente. (HAYLES, 1999, p.243, tradução nossa) ${ }^{13}$.

Tal discussão acerca da capacidade das vidas artificiais de evoluírem rapidamente dentro deste processo de informação acaba não sendo questionável, tendo em vista o quanto as máquinas são capazes de evoluir muito mais rapidamente que a evolução da espécie humana de outras espécies. No entanto, cabe observar também a discussão sobre informação também ligada ao que chamamos de consciência pelo viés humano. A consciência humana, seria a mesma informação contida nas máquinas e, pensando que as capacidades físicas já não seriam já estariam sanadas no processo de semelhanças físicas entre corpos robóticos e corpos humanos, o que ainda poderia fazer com que a vida artificial não fosse reconhecida também como um tipo de vida pós-humana seria a capacidade de sentir emoções e interagir de forma afetiva.

As manifestações de afeto, principalmente quando se relaciona a vida artificial com o que se entende como vida humana é muito relevante, pois a capacidade humana de manifestar emoções e sentimentos é parte da própria constituição do conceito de humano. Em um artigo intitulado "Problems and Methods in the History of Emotions", de Barbara Rosenwein (2010) é discutido e apresentado algumas perspectivas sobre as origens das emoções, sendo uma delas interessante quando se observa o modo de manifestação de emoção e afeto de vida artificial.

Nosso ambiente atual afeta a expressão gênica e, em alguns casos (em organismos muito simples e em níveis celulares especializados) induz mutações não aleatórias em genes. Mais importante ainda, grande parte da evolução humana não tem nada a ver com genes: os sistemas de

\footnotetext{
12 Do original: [...] distinguishing between natural and Artificial Life, human and machine intelligence, will be difficult or impossible.

13 Do original: Humans evolved through a combination of chance and self-organizing processes until they reached the point where they could take conscious advantage of the principles of self-organization to create evolutionary mechanisms. They used this ability to build machines capable of self-evolution. Unlike humans, however, the machine programs are not hampered by the time restrictions imposed by biological evolution and physical maturation. They can run through hundreds of generations in a day, millions in a year. Until very recently, humans have been without peer in their ability to store, transmit, and manipulate information. Now they share that ability with intelligent machines. To foresee the future of this evolutionary path, we have only to ask which of these organisms, competing in many ways for the same evolutionary niche, has the information-processing capability to evolve more quickly.
} 
herança celular, comportamental e simbólica são epigenéticos. A evolução adaptativa por meio desses mecanismos - que estão em andamento - é muito mais rápida do que a evolução genética. Essas observações dão lastro à ideia de que as emoções podem mudar com o tempo e que a história das emoções não é apenas possível, mas essencial para a compreensão da condição humana. (ROSENWEIN, 2010, p.08, tradução nossa) ${ }^{14}$

Como a relação entre emoção não está ligada a um fator genético, seria possível afirmar que os corpos humanizados criados a partir da vida artificial poderiam desenvolver emoções, manifestações de afeto com o convívio social. Essa afirmação é reforçada quando se entende que esses corpos humanizados foram criados para desempenharem as mesmas funções dos humanos e, portanto, poderiam e estariam aptos a conviverem socialmente assim como os humanos. Se a veracidade dessas manifestações fosse questionada, também poderia ser questionada a própria autenticidade das manifestações de emoções dos humanos que nem sempre dizem e/ou demonstram exatamente o que estão sentindo.

[...] [E]moções muitas vezes têm funções e significados superdeterminados. Não devemos nos preocupar se uma emoção é autêntica, a menos que a comunidade emocional particular que estamos estudando esteja preocupada com a autenticidade. Mesmo em nossos dias, quando a sinceridade é altamente valorizada, a maioria dos estudos psicológicos das emoções usa rostos postulados. Não há nenhuma questão de emoção "real". E com boas razões: as emoções são, entre outras coisas, sinais sociais (embora, como tenho argumentado, não sejam sinais sociais universais). Se uma emoção é a resposta padrão de um grupo particular em certos casos, a questão não deve ser se trai o sentimento real, mas sim porque uma norma é obtida em detrimento de outra. (ROSENWEIN, 2010, p.21, grifos da autora, tradução nossa) ${ }^{15}$

Acredita-se, portanto, que a criação de corpos humanizados respeitando os parâmetros e definições previstas dentro do conceito de vida artificial promoveria uma ampliação do próprio conceito de transumano e pós-humano, pois além de haver uma inversão de princípios que seriam a base do conceito de pós-humano, partindo do humano e seguindo para o corpo alterado, também se estaria explorando um novo conceito de vida que estaria apto para conviver tecnologicamente e socialmente com os humanos.

Ainda que os estudos acerca do conceito de vida artificial estejam recentes e não haja um previsão para que seja criado um corpo humano inteiramente a partir de vida artificial, é importante pensar que a criação da robô Sophia, por exemplo, já é um indicativo da intenção do homem de se tornar criador de uma nova espécie que seja compatível e semelhante aos humanos e a vida artificial parece ser a teoria que mais permitiria que houvesse um melhoramento também para os corpos humanos, tendo em vista que se esse corpo robótico for compatível ao corpo humano, os seus avanços tecnológicos também seriam uteis a espécie humana e a autonomia da espécie Homo sapiens.

\footnotetext{
${ }^{14}$ Do original: Our current environment affects gene expression and in some instances (in very simple organisms and at specialized cell levels) induces non-random mutations in genes. Most importantly, much of human evolution has nothing to do with genes: cellular, behavioral, and symbolic inheritance systems are epigenetic. Adaptive evolution through these mechanisms-which are ongoing-is far more rapid than genetic evolution. These observations give ballast to the idea that emotions may change over time and that a history of the emotions is not only possible, but essential to understanding the human condition.

${ }^{15}$ Do original: [...] emotions often have over-determined functions and meanings. We should not worry about whether an emotion is authentic unless the particular emotional community that we are studying is itself concerned about authenticity. Even in our own day, when sincerity is highly valued, most psychological studies of emotions use posed faces. There is no question of "real" emotion there at all. And with good reason: emotions are, among other things, social signals (although, as I have been arguing, not universal social signals). If an emotion is the standard response of a particular group in certain instances, the question should not be whether it betrays real feeling but rather why one norm obtains over another.
} 


\section{Conclusão}

Se de um lado as alterações nos corpos mais presentes na sociedade não estão discutindo o melhoramento e a autonomia dos humanos, mas sim uma excessiva adaptação a padrões estéticos que reforçam características em corpos de acordo com o que é determinado como belo e perfeito dentro de uma perspectiva ocidental, por outro os avanços tecnológicos nos estudos da robótica estão aproximando o ideal de corpo humano para o ideal de corpo robótico. Para além das semelhanças físicas, é importante manifestar também o quanto o comportamento das vidas artificiais visa se assemelhar ao comportamento do seu respectivo biológico, o que pode ser um indicativo de aproximações entre máquina e humano, pois

[...] tornar-se pós-humano significa muito mais do que ter próteses implantadas no corpo. Significa vislumbrar seres humanos como máquinas de processamento de informações com semelhanças fundamentais com outros tipos de máquinas de processamento de informações, especialmente computadores inteligentes. (HAYLES, 1999, p.246, tradução nossa) ${ }^{16}$.

Essas questões acabam se tornando mais relevantes a partir do momento em que máquinas passam a ganhar direitos humanos, passando a assumir status de humano ou ainda colocando máquina e humano em um nível de igualdade até então não reconhecido entre outras espécies no nível biológico. O conceito de vida artificial, portanto, passa a ressignificar os próprios conceitos de transumanismo e pós-humanismo, pois apesar de não partir de um corpo humano, aponta seus esforços para inúmeras tecnologias que aproximam os corpos humanos dos corpos robóticos com a intenção, ainda que não garantida neste momento, de quase não identificáveis diferenças.

Se os humanos e os corpos humanos passam a ser constantemente alterados para ganharem maior autonomia, promovendo não somente o melhoramento do corpo, mas da espécie Homo sapiens e todas essas mudanças são promovidas pelo aprimoramento e investimento da tecnologia diretamente nesses corpos, se pode afirmar que os humanos estão cada vez mais dependentes da tecnologia em seus corpos e, consequentemente, cada vez mais maquinizam os seus corpos. O desenvolvimento da vida artificial, em contrapartida, parece estar cada vez mais procurando fundir os humanos e as máquinas dentro de uma idealização de ciborgue que já não partiria mais do humano e seria o hibrido, o que confunde e quebra as barreiras e traz a pós-humanidade, bem como o conceito de imortalidade e domínio do corpo mais próximo e possível para a máquina que se torna transumana e pós-humana, como no caso do robô Andrew de Isaac Asimov (1976), em O Homem Bicentenário, que já previa a constante adaptação das máquinas para serem reconhecidas como humanas.

Conclui-se, portanto, que as alterações nos corpos são as mais significativas para a aproximação entre transumanos, pós-humanos, ciborgues e aqueles que possuem a origem não-biológica e, se ainda parece distante que corpos robóticos se tornem impossíveis de serem diferenciados de humanos, não é equivocado dizer que tais mudanças já transformam os humanos e ampliam nossas próprias percepções de vida e alertam para o que pode acontecer se tais mudanças não ocorreram de forma adequada e amparada por estudos sociais.

\section{Referências}

ASIMOV, Isaac. O Homem Bicentenário. 1. ed. Porto Alegre: L\&PM Pocket, 1997, 120p. Tradução: Milton Persson.

\footnotetext{
${ }^{16}$ Do original: [...] becoming a posthuman means much more than having prosthetic devices grafted onto one's body. It means envisioning humans as information-processing machines with fundamental similarities to other kinds of information-processing machines, especially intelligent computers.
} 
BEDAU, Mark A. Artificial Life. In: MATTHEN, Mohan; STEPHENS, Christopher(Ed.). Handbook of The Philosophy of Biology. North-Holland: Elsevier, 2007, p. 586 - 603.

BLACKFORD, Russel. The Great Transition: Ideas and Anxieties. In: MORE, Max; VITA-MORE, Natasha (Ed.). The transhumanist reader: classical and contemporary essays on the science, technology, and philosophy of the human future. United Kingdom: Wiley-Blackwell, 2013, p. $421-429$.

BRODERICK, Damien. Trans and Post. In: MORE, Max; VITA-MORE, Natasha (Ed.). The transhumanist reader: classical and contemporary essays on the science, technology, and philosophy of the human future. United Kingdom: Wiley-Blackwell, 2013, p. 430 - 437.

CHAVES, Noêmia de Sousa. O Conceito de Pessoa Humana: Abordagens Bioética(s) em Engelhardt Jr. e Lucien Sève. Revista Estudos Filosóficos, Minas Gerais, Universidade Federal de São José DelRei, vol. 4, n.02, p. $62-83,2010$.

CYBORG FOUNDATION. About Neil Harbisson. Disponível em: http://www.cyborgfoundation. com/about. Acesso em: 19 de novembro de 2018.

CYBORG FOUNDATION. About Moon Ribas. Disponível em: http://www.cyborgfoundation. com/about. Acesso em: 19 de novembro de 2018.

CYBORG FOUNDATION. Ways we relate to technology. Disponível em: http://www. cyborgfoundation.com/. Acesso em: 20 de dezembro de 2018.

DICK, Philip K. Androides sonham com ovelhas elétricas?. 1. ed. São Paulo: Aleph, 2015, 191p. Tradução: Ronaldo Bressane.

GARNER, Stephen. The Hopeful Cyborg. In: COLE-TURNER, Ronald (Ed.). Transhumanism and transcendence: Christian hope in an age of technological enhancement, USA: Georgetown University Press, 2011, p. 87 - 100.

HANSON ROBOTICS. Sophia. Disponível em: http://www.hansonrobotics.com/robot/sophia/. Acesso em: 19 de novembro de 2017.

HARAWAY, Donna. J. Manifesto ciborgue: Ciência, tecnologia e feminismo-socialista no final do século XX. In: TADEU, T. (Org.); HARAWAY, D.; KUNZRU, H. Antropologia do ciborgue: as vertigens do pós-humano. Belo Horizonte: Autêntica Editora, 2009, p. 33 - 118. Tradução: Tomaz Tadeu.

HAYLES, N. Katherine. How we became posthuman: virtual bodies in cybernetics, literature, and informatics. Chicago: University of Chicago, 1999, 350p.

HUXLEY, Aldous. Admirável Mundo Novo. São Paulo: Ed. Globo, 2014, 312p. Tradução: Lino Vallandro e Vidal Serrano.

I LISTEN TO COLOR with Neil Harbisson. Ted Talks Psychology., 2012, 9:36 min, son., color. Disponível em: http://tedtalkspsychology.com/i-listen-to-color-with-neil-harbisson/. Acesso em: 09 de novembro de 2017.

KUNZRU, Hari. Genealogia do ciborgue. In: TADEU, T. (Org.); HARAWAY, D.; KUNZRU, H. Antropologia do ciborgue: as vertigens do pós-humano. Belo Horizonte: Autêntica Editora, 2009, p. 119 - 126. Tradução: Tomaz Tadeu.

MARKS DE MARQUES, Eduardo; PEREIRA, Anderson Martins. A justaposição do pós-humano e do transumano no gênero distopia: Uma análise das trilogias Divergente e A 5⿳亠丷厂 Onda. Ilha do Desterro, Florianópolis, v. 70, p. 119-127, 2017.

MORE, Max. The Philosophy of Transhumanism. In: MORE, Max; VITA-MORE, Natasha (Ed.). The transhumanist reader: classical and contemporary essays on the science, technology, and philosophy of the human future. United Kingdom: Wiley-Blackwell, 2013, p. 03 - 17.

MORE, Max; VITA-MORE, Natasha (Ed.). The transhumanist reader: classical and contemporary essays on the science, technology, and philosophy of the human future. United Kingdom: WileyBlackwell, 2013, 460p. 
NEGRIM, Llewellyn. Appearance and Identity: Fashioning the Body in Postmodernity. 1. ed. United States: Palgrave Macmillan, 2008, 209p.

OLIVEIRA, Fatima Regis. Ficção Científica: uma narrativa da subjetividade homem-máquina. Revista Fluminense, Rio de Janeiro:Universidade Federal Fluminense, vol. 9, p. 177 - 198, 2003.

OLIVEIRA, Fátima Regis. Os autômatos da ficção científica: reconfigurações da tecnociência e do imaginário tecnológico. Revista Intexto, Porto Alegre: UFRGS, v. 1, p. 1 - 15, 2006.

PEGORARO, Olinto. Fundamentos Filosóficos da Bioética. In: SYMPOSIUM DE FILOSOFIA, Pernambuco. Anais... Pernambuco: Universidade Católica de Pernambuco, v.1, 1998, p. 56 - 63.

REVISTA GALILEU. Arábia Saudita torna-se primeiro país a conceder cidadania para um robô: A história da robô Sophia parece o enredo de 'Ex-Machina', mas é vida real. 30 de outubro de 2017. Disponível em: http://revistagalileu.globo.com/Tecnologia/noticia/2017/10/arabia-saudita-tornase-primeiro-pais-conceder-cidadania-para-um-robo.html. Acesso em: 14 de novembro de 2018.

ROSENWEIN, Barbara H. Problems and Methods in the History of Emotions. Passions In Context. International Journal for the History and Theory of Emotions, 2010, p.1-32. Disponível em: http:// www.passionsincontext.de/index.php?id=557. Acesso em: 28 de maio de 2018.

RÜDIGER, Francisco. Cibercultura e Pós-humanismo: Exercícios de arqueologia e criticismo. 1. ed. Porto Alegre: EDIPUC, 2008, 238p.

TADEU, Tomaz. Nós, ciborgues: O corpo elétrico e a dissolução do humano. In: TADEU, T (Org.); HARAWAY, D.; KUNZRU, H. Antropologia do ciborgue: as vertigens do pós-humano Belo Horizonte: Autêntica Editora, 2009, p. 7 - 16.

TRINCA, Tatiane. O corpo-imagem na "cultura do consumo": uma análise histórico-social sobre a supremacia da aparência no capitalismo avançado, 2008, 154 f. Dissertação (Mestrado em Ciências Sociais), Universidade Estadual Paulista, Marília, 2008.

VINGE, Vernos. Technological Singularity. In: In: MORE, Max; VITA-MORE, Natasha (Ed.). The transhumanistreader: classical and contemporary essays on the science, technology, and philosophy of the human future. United Kingdom: Wiley-Blackwell, 2013, p. $365-375$.

WINTERSON, Jeanette. Deuses de Pedra. Rio de Janeiro: Record, 2012, 288p. Tradução: Sérgio Duarte. 